\title{
Arborização de acompanhamento viário em conjuntos habitacionais de Cuiabá-MT
}

\section{Monitoring of road afforestation in hou-sing estates of Cuiabá-MT}

\author{
${ }^{1}$ Douglas Luciano Lopes Gallo, ${ }^{2}$ Louise Logsdon \\ ${ }^{1}$ Instituto Federal de Educação, Ciência e Tecnologia de São Paulo, Campus \\ Registro.(douglas.luciano@yahoo.com.br) \\ ²Instituto Federal de Educação, Ciência e Tecnologia de Mato Grosso, Campus Cuiabá.
}

\begin{abstract}
RESUMO: Este estudo buscou diagnosticar a situação atual da arborização de acompanhamento viário de dois loteamentos voltados à habitação de interesse social (HIS) da cidade de Cuiabá-MT. Tratam-se do Residencial Morro de Santo Antônio, implantado em 2001, e do Residencial Altos do Parque, cujas moradias foram entregues em 2014. Os dados foram coletados com auxilio de uma ficha de campo, registro fotográfico e medições com trena metálica. A variável principal do estudo foi a quantidade de árvores por quilômetro de calçada. A quantidade média encontrada nos dois conjuntos habitacionais foi de 69 árvores por quilômetro de calçada, ou uma árvore a cada 14 metros de calçada. A espécie mais abundante é o Oiti (Licania tomentosa) com frequência de $61,22 \%$ dos casos, e a grande maioria das árvores encontradas são de pequeno porte. Conclui-se que a arborização de acompanhamento viário nos loteamentos estudados é deficiente, especialmente no Residencial Altos do Parque, e se concentra em um número muito pequeno de espécies, sendo necessária uma maior diversificação. Novos estudos para além dos aspectos abordados se fazem necessários, especialmente com abordagens qualitativas da paisagem urbana.
\end{abstract}

Palavras chave: Habitação de interesse social. Arborização Urbana. Espaços públicos.

ABSTRACT: This study aimed to diagnose the current situation of the road afforestation in two housing estates of Cuiaba-MT - the "Morro de Santo Antônio" Residential, implemented in 2001, and the "Altos do Parque" Residential, whose homes were recently delivered in 2014. The data were collected with the aid of a field record, photographic record and measurements with metallic tape. The primary study endpoint was the abundance of trees, represented by the amount of trees per kilometer of pavement. On average were identified 69 trees per kilometer of pavement or a tree every 14 meters of sidewalk. The most abundant species was the Oiti (Licania tomentosa $-61.22 \%$ of cases) and the large majority is small. It concludes that afforestation of road monitoring the studied settlements is poor, especially in the "Altos do Parque" Residential, which focuses on some species, requiring greater diversification. New studies in addition to the points raised are necessary, especially with qualitative approaches to urban landscape.

Keywords: Social Housing. Urban Forestry. Public Spaces.

\section{INTRODUÇÃO}

O déficit habitacional brasileiro é grande e histórico, tendo sido estimado em 5,792 milhões de unidades no ano de 2012 (FUNDAÇÃO JOÃO PINHEIRO, 2014). Para suprir essa necessidade, vários conjuntos habitacionais foram sendo implantados em todo o país, alterando os limites, as características e a própria paisagem das cidades, de uma maneira não muito positiva na maioria das vezes, como aponta Bonduki (2004), com relação ao Banco Nacional de Habitação (BNH) e Amore (2005), com relação ao Programa Minha Casa, Minha Vida (PMCMV).

Analisar a qualidade dos empreendimentos habitacionais de interesse social que estão sendo construídos se faz necessário e, além dos aspectos construtivos e de qualidade de projeto, deve-se considerar o espaço público e as áreas livres dos mesmos, uma vez que ali se constroem e se consolidam relações de sociabilidade e vizinhança. As habitações de interesse social no Brasil são construídas respeitando-se áreas mínimas de espaço e o lote geralmente possui o tamanho mínimo permitido por lei, o que aumenta ainda mais a importância dos espaços públicos como espaços de lazer e convivência. 
São inegáveis os benefícios de um planejamento da área urbana que priorizem a presença e a distribuição adequada dos espaços livres, seja pelas qualidades ambientais que propiciam, seja pelo acesso da população de forma equitativa.

Com a atualidade das discussões sobre aquecimento global e a constatação de dias cada vez mais quentes, aumenta o enfoque e interesse pela arborização urbana, especialmente em relação ao conforto térmico, sem considerar, muitas vezes, os microclimas das cidades. As vantagens da arborização urbana são destacadas pelos benefícios psicológicos, efeito estético, sombreamento, proteção e direcionamento dos ventos, amortecimento do som, diminuição da poluição sonora, redução do impacto das chuvas e preservação da fauna (OLIVEIRA et al, 2009).

A arborização urbana é defendida e preconizada nos ambientes urbanos, ao mesmo tempo em que a dinâmica do desenvolvimento urbano promove a retirada progressiva da vegetação nativa, provocando mudanças nos microclimas, topoclimas e mesoclimas, constituindo desta forma um clima urbano, diverso do entorno rural (COSTA e FERREIRA, 2009) e desligado de sua identidade florística local.

Em função das atividades fisiológicas desempenhadas pela vegetação, ela é capaz de promover significativas melhorias no ambiente urbano, principalmente no que se refere à redução da poluição atmosférica, à minimização das temperaturas, ao conforto luminoso e acústico, além de promover bem-estar físico e psíquico ao ser humano, atuando, consequentemente, na sua qualidade de vida (COSTA e FERREIRA, 2009). Portanto, a arborização urbana deve ser planejada com objetivos estéticos, sociais, de identidade local, e de amenização ambiental (HUTHER e MASCARÓ, 2008).

Em uma cidade de clima quente, como é o caso de Cuiabá, os encontros e usos dos espaços públicos - e de forma particular nas calçadas - são muito influenciados pelo sombreamento dos mesmos, quando o microclima torna-se mais agradável para o encontro.

Embora a importância da consideração do clima no planejamento urbano seja reconhecida, constata-se que muito pouco do conhecimento disponível da climatologia urbana é usado no planejamento das cidades. O crescimento e a melhoria da qualidade nos centros urbanos não estão baseados apenas em novas e bem sucedidas construções, mas, na inclusão de espaços livres sustentáveis, na revitalização de espaços abertos e na preservação de reservas naturais importantes para a manutenção do equilíbrio ambiental. A presença ou ausência de vegetação, a função desenvolvida, porte e localização dessa vegetação podem fornecer indicadores importantes sobre o papel e a função desempenhada pelo espaço público no ambiente urbano (OLIVEIRA, 2011).

Tendo em vista que os conjuntos habitacionais de interesse social deveriam ser entregues pelas construtoras com toda infraestrutura pronta, inclusive a arborização urbana, intentou-se conhecer como alguns projetos foram elaborados e executados, comparando-se as diferenças em relação ao tempo da execução, se haveriam diferenças em um loteamento mais antigo, lançado através do Programa de Arrendamento Residencial (PAR), e outro mais recente, lançado pelo Programa Minha Casa, Minha Vida (PMCMV).

O estudo se justifica devido à importância da arborização urbana ser inquestionável, bem como o papel dos espaços públicos, em particular das calçadas para a sociabilidade na cidade contemporânea. Os conjuntos residenciais de interesse social não têm se preocupado com a qualidade espacial, sob esta ótica simplista as unidades residenciais, posto a necessidade de oferecerem uma moradia a baixo custo, tem apresentado projetos com áreas mínimas e padronização excessiva, indicando uma involução da qualidade das soluções propostas. Para além da lógica arquitetônica e de projeto é importante refletir sobre a qualidade ambiental dos espaços urbanos destes residenciais e suas potencialidades como espaços integradores e geradores de qualidade de vida. 
Gallo D. L. L.; Logsdon L.; Arborização de acompanhamento viário em conjuntos habitacionais de Cuiabá-MT. E\&S - Engineering and Science, (2017), 6:1.

Portanto o objetivo do estudo foi diagnosticar a situação atual da arborização de acompanhamento viário e as configurações espaciais dos espaços públicos em dois conjuntos habitacionais de interesse social de Cuiabá-MT: o Residencial Morro de Santo Antônio e o Residencial Altos do Parque.

\section{REVISÃO BIBLIOGRÁFICA}

\section{Arborização Urbana}

Com as atuais discussões sobre aquecimento global e a constatação de dias cada vez mais quentes, aumenta o enfoque e interesse pela arborização urbana, especialmente em relação ao conforto térmico, sem considerar, muitas vezes, os microclimas das cidades. As vantagens da arborização urbana são destacadas pelos benefícios psicológicos, efeito estético, sombreamento, proteção e direcionamento dos ventos, amortecimento do som, diminuição da poluição sonora, redução do impacto das chuvas e preservação da fauna (OLIVEIRA et al, 2009).

A arborização urbana é defendida e preconizada nos ambientes urbanos, ao mesmo tempo em que a dinâmica do desenvolvimento urbano promove a retirada progressiva da vegetação nativa, provocando mudanças nos microclimas, topoclimas e mesoclimas, constituindo desta forma um clima urbano, diverso do entorno rural e desligado de sua identidade florística local (COSTA e FERREIRA, 2009).

A presença ou ausência de vegetação, a função desenvolvida, seu porte e sua localização podem fornecer indicadores importantes sobre o papel e a função desempenhados pelo espaço público no ambiente urbano. Com vista no exposto por Costa e Ferreira (2009), é possível inferir que a arborização não se limita ao plantio de árvores em ruas, praças e jardins, ela deve atingir objetivos como ornamentação, melhoria de microclima e diminuição da poluição.

É importante ressaltar que, no Brasil, a arborização urbana começou a ser sistematicamente implantada a partir da segunda metade do século XX, principalmente em função do grande aumento da população das cidades, que gerou a necessidade da criação de espaços urbanos arborizados que proporcionassem lazer e bem estar psicológico à população (OLIVEIRA, 2011).

\section{A cidade de Cuiabá-MT}

A cidade de Cuiabá teve seus processos de espacialização e constituição urbana como reflexo de uma dicotomia entre suas referências histórico-culturais e o moderno, conflito que nasce entre seu passado, representado pela rica cultura e patrimônio e a necessidade de modernização, face aos problemas de crescimento urbano e mesmo à negação de sua condição cultural pregressa. A cidade surge definitivamente a partir do início do século XVIII, sobre a riqueza do ouro e sua exploração num Brasil colonial, de ocupação litorânea. Enfrentou períodos alternados de crise e prosperidade, oscilando entre o declínio da mineração, sucesso na exploração do seringal e cana de açúcar (final do século XIX e início do XX), passando por décadas de marasmo econômico até a divisão do estado em 1977. A partir deste momento ocorre nova fase de pujança fundamentada na produção agroindustrial (SILVA, 2007).

O processo de descaracterização do seu Centro Histórico se deu a partir do final da década de 50, iniciado pela obsessão pela modernização da capital pela iniciativa pública, com demolição de vários edifícios da arquitetura colonial cuiabana. A capital teve altos índices de crescimento populacional nas décadas de 1960 e 1970, incentivados pela política de ocupação da região amazônica e do centro oeste pelo Governo Federal. Com este processo 
ocorreu a degradação dos serviços urbanos, invasões e ocupações de áreas de reserva, constituição de habitações irregulares, pressão e especulação imobiliária, impermeabilização e verticalização urbana, implicando em degradação da qualidade de vida e impacto sobre o meio ambiente urbano (SILVA, 2007).

Paralelamente a isso, Silva (2007) observa que o traçado colonial cuiabano foi desafiado pelo automóvel e seu imaginário de progresso. Surgindo a necessidade de providenciar uma circulação eficiente para a cidade de traçado sinuoso e ruas revestidas de paralelepípedos. $\mathrm{Na}$ década de 1970 ocorreu grande pressão comercial imobiliária na área central da cidade, decorrente do "Milagre econômico". A partir da década de 1980 surgiu a discussão sobre a importância em preservar o patrimônio, pressionando-se pela preservação do Centro Histórico de Cuiabá. A Cuiabá contemporânea é uma capital que assume seu papel de metrópole regional, mesmo tendo uma composição paradoxal e complexa, refletida nos seus conflitos, segregação sócio espacial, exploração e destruição dos recursos naturais e dinamismo econômico.

No caso do Mato Grosso, por ser estado de urbanização recente, há escassez de estudos para além dos aspectos históricos e econômicos. O ambiente urbano e seus espaços livres têm sido produzidos de formas específicas, incorporando temas de inclusão recente no repertório legal que rege a formação e gestão de cidades e a criação das formas urbanas, porém com resultados ainda não documentados de forma sistemática, portanto, sequer discutidos.

\section{Habitação de Interesse Social}

Segundo Santos (2013), a urbanização brasileira se avoluma e a residência dos trabalhadores agrícolas é cada vez mais urbana, nesta dicotomia entre o Brasil urbano e o Brasil rural, onde no primeiro o nexo essencial deve-se a atividades de relação complexas, enquanto no segundo a atividades mais diretamente produtivas. $O$ perfil urbano se torna complexo, com tendência à onipresença da metrópole, porém paralelamente, ocorre certa "involução" metropolitana, onde o crescimento econômico das grandes cidades é menor que o das regiões agrícolas dinâmicas e de suas cidades regionais. As grandes cidades tornam-se polos da pobreza, o lugar com mais força e capacidade de atrair e manter gente pobre, as vezes em condições sub-humanas.

Para o autor, a cidade em si torna-se criadora de pobreza, tanto como relação social como materialidade. O modelo socioeconômico de que é suporte e sua estrutura física faz com que os habitantes da periferia sejam ainda mais pobres. $\mathrm{O}$ nível da urbanização, o desenho urbano, as manifestações das carências da população são realidades que devem ser analisadas à luz dos subprocessos econômicos, políticos e socioculturais.

A urbanização brasileira se desenvolveu mais expressivamente a partir do século XVIII, amadurecendo no século XIX e apenas no século XX atingiu as características atuais. Entre o fim do período colonial até o final do século XIX o índice de urbanização pouco se alterou, entre 1890 e 1920 cresceu aproximadamente 3\% e somente no período de 1920 a 1940 esta taxa triplica, chegando a 31,24\% (SANTOS, 2013).

A industrialização que se afirma a partir de 1930 e vai até o fim da Segunda Guerra Mundial constituiu um caminho de avanço relativo de iniciativas de fortalecimento do mercado interno, com grande desenvolvimento das forças produtivas, diversificação, assalariamento crescente e modernização da sociedade. Em 1950, o processo de industrialização entra em nova etapa, passando a produzir bens duráveis e até mesmo bens de produção, porém a dependência dos centros de decisões externos ao país se aprofunda, ampliando a inserção subalterna do país na divisão internacional do trabalho (MARICATO, 2011). 
Nesse momento, os Institutos de Aposentadoria e Pensão (IAPs) surgem visando solucionar a questão habitacional da classe trabalhadora ligada à indústria e comércio. Houve uma preocupação com a racionalização, produção em larga escala de moradias e normatização dos materiais. O nascimento da habitação como questão social reformulou a arquitetura e o urbanismo e a forma de produção, incorporando os pressupostos do movimento moderno que propunha a edificação em série, com padronização e pré-fabricação, como instrumentos para atender às grandes demandas existentes nas cidades marcadas pela presença do operariado (BONDUKI, 2004).

A Fundação da Casa Popular, criada em 1946, foi o primeiro órgão federal criado com o objetivo de centralizar a política habitacional. Através dela, propunha-se financiar não apenas casas, mas também infraestrutura urbana, produção de materiais de construção, estudos e pesquisas (VILLAÇA, 1986; BOTTEGA, 2007). Dada a fragilidade institucional e financeira dessa fundação, suas realizações foram pouco expressivas: limitavam-se a construção de conjuntos habitacionais em parceria com as prefeituras, que doavam o terreno e a infraestrutura. Foi dessa forma que a FCP construiu, por exemplo, o primeiro conjunto habitacional de interesse social em Cuiabá-MT, o Popular, na década de 1950 (CASTOR, 2007). Os IAPs, ao contrário, realizaram uma produção habitacional significativa de grande valor arquitetônico e urbanístico, visto a influência dos ideais do movimento moderno (BONDUKI, 2004).

Na década de 1950, ocorreu grande crescimento da população urbana e agravamento dos problemas habitacionais. Dadas as pressões populares existentes nesse período, uma das primeiras ações do novo governo militar, após o golpe, foi o estabelecimento do Banco Nacional da Habitação (BNH), que buscou centralizar as ações do Estado no que diz respeito à produção e distribuição de unidades habitacionais. Era o órgão gestor do Fundo de Garantia por Tempo de Serviço (FGTS), e o órgão regulador do Sistema Brasileiro de Poupança e Empréstimo (SBPE), que eram os dois subsistemas do Sistema Financeiro da Habitação (SFH). A diferença entre o FGTS e o SBPE é que o primeiro era destinado a financiar a produção de moradias para a população de baixa renda, enquanto o segundo atendia às classes média e alta (KOWARICK e BONDUKI, 1988).

A política habitacional do BNH teve uma inegável importância para a produção massiva de habitação, no sentido do acesso à moradia, mas os componentes dessa política são questionáveis, sobretudo o urbano. Isso porque, mesmo com a atribuição de promover desenvolvimento urbano e habitação, o sistema produzia conjuntos habitacionais sem infraestrutura adequada, de dimensões extremamente ampliadas constituindo verdadeiras cidades periféricas com uma forte marca de segregação sócio territorial em relação à cidade constituída através do parcelamento tradicional (BONDUKI, 2007).

Após a extinção do BNH, o Brasil encontrou-se numa situação complicada, pois havia grande número de inadimplência e o déficit habitacional ainda não havia sido solucionado. A constituição Federal de 1988 tornou obrigatório o Plano Diretor para os municípios com mais de 20 mil habitantes, assim a problemática fundiária urbana passou a ser regida pelo disposto na Constituição e pelas Leis Orgânicas Municipais. Sob o comando do presidente Fernando Collor de Mello, em 1990, a crise habitacional foi agravada, e com o Plano de Ação Imediata para a Habitação volta-se a direcionar-se ao capital imobiliário privado.

A partir de 1995, no governo Fernando Henrique Cardoso, começa a existir uma reforma mais efetiva nas áreas de planejamento de habitação, destacando-se o papel desempenhado pela Caixa Econômica Federal e as novas linhas de financiamento voltadas para projetos habitacionais estaduais e municipais (SANTANA, 2006).

Nesta época foram criados dois importantes programas habitacionais: o Programa da Carta de Crédito e o Programa de Arrendamento Residencial (PAR). Segundo Metello et al (2005), o primeiro utilizava recursos do FGTS para conceder cartas de créditos a pessoas 
físicas a pessoas físicas com concentração de renda mensal na faixa de 01 a 05 salários mínimos, destinados para a aquisição de imóvel novo ou usados; construção em terreno próprio e para reforma de moradia. Para a construção de moradias, o programa também podia abranger pessoas jurídicas, através das cartas associativas ou de financiamento. Já o PAR utilizava recursos do FAR (Fundo de Arrendamento Residencial - composto pelos fundos do FGTS e do Governo Federal) e visava a produção ou recuperação de empreendimentos habitacionais, sendo o acesso à moradia através de contrato de arrendamento pessoal, com opção de compra futura. Atendia famílias com faixa de renda entre três e seis salários mínimos.

Em 2003, quando foi criado o Ministério das Cidades, o governo federal trabalhava em cuidadoso processo de construção política de um sistema de cidades e de habitação de interesse social. Mas o momento parecia exigir respostas mais rápidas. O Contexto da crise econômica junto com o enfraquecimento do Ministério das Cidades no seu papel de formulador e condutor da política urbana levou o governo a acolher uma proposta do setor da construção civil, apostando no potencial econômico da produção de habitação em massa (AMORE, 2015).

Foi dessa forma que, então, foi promulgada a Lei Federal $\mathrm{n}^{\circ} 11.977$ de 7 de julho de 2009 que criou o Programa Minha Casa Minha Vida (PMCMV), com a finalidade de criar mecanismos de incentivo à produção e à aquisição de novas unidades habitacionais por famílias com diferentes níveis de renda, entre zero e 10 (dez) salários mínimos (BRASIL, 2009). Sua produção foi muito expressiva em número de unidades construídas. Para se ter uma ideia, em apenas cinco anos foram contratados um número equivalente a $80 \%$ das unidades que o BNH financiou nos seus 22 anos de existência, sendo que cerca da metade dessas unidades já tinha sido entregue até 2015 (AMORE, 2015).

Pode-se dizer que o PMCMV é, na origem, um programa econômico. Foi concebido pelos ministérios da Casa Civil e da Fazenda, em diálogo com o setor imobiliário e da construção civil, e lançado como uma forma declarada de enfrentamento da chamada crise dos subprimes americanos que recentemente tinha provocado a quebra de bancos e impactado a economia financeirizada mundial (AMORE, 2015).

Um grande problema que cerca a produção habitacional do PMCMV é justamente a repetição dos erros reconhecidos do $\mathrm{BNH}$, de produção periférica em locais mal servidos por infraestrutura urbana, tendo em vista a desarticulação da produção habitacional em relação às matérias urbanísticas e às ações municipais de regulação do uso e ocupação do solo, que estariam apoiadas na efetivação da função social da propriedade. A questão da terra, o nó da política urbana brasileira, e da segregação socioespacial são apontadas como o principal gargalo que o Minha Casa Minha Vida não tem enfrentado, com consequências ainda difíceis de serem previstas (AMORE, 2015).

\section{MÉTODOS EMPREGADOS}

O estudo foi realizado na cidade de Cuiabá, localizada na depressão cuiabana, centro geodésico da América do Sul, definida pelas coordenadas geográficas 15³5'56" latitude Sul e $56^{\circ} 06^{\prime} 05^{\prime}$ longitude Oeste, e sua altitude varia entre 145 e 250 metros. O município de Cuiabá é cercado por três grandes biomas: Amazônia, Cerrado e Pantanal. O clima de Cuiabá é tropical e úmido, as chuvas se concentram de outubro a abril. A temperatura máxima pode chegar aos $40{ }^{\circ} \mathrm{C}$ nos meses mais quentes e a mínima em julho, o mês mais frio, é de $16,6^{\circ} \mathrm{C}$.

Foram analisados dois conjuntos habitacionais de interesse Social: Residencial Morro de Santo Antônio e Residencial Altos do Parque. O primeiro é um dos mais antigos conjuntos habitacionais promovidos pelo PAR (Programa de Arrendamento Residencial), entregue em 2001, e o segundo foi entregue em 2014 pelo Programa Minha Casa, Minha Vida. 
Gallo D. L. L.; Logsdon L.; Arborização de acompanhamento viário em conjuntos habitacionais de Cuiabá-MT. E\&S - Engineering and Science, (2017), 6:1.

\section{Característica do Estudo}

De acordo com Milano (1994) a arborização urbana é fundamentalmente dependente do planejamento urbano, especialmente das características do sistema viário, definindo suas características quanti-qualitativas. Para o autor, levantar o número total de árvores, através de inventários totais (censo) é inviável, pela quantidade de tempo e recursos necessários para sua realização, e, por isso, o inventário por amostragem é geralmente o mais utilizado nas pesquisas.

O sistema de amostragem aleatório foi apontado por Milano (1994) como o mais comum, devido às características gerais da arborização das cidades. Meneghetti (2003) utilizou o método de amostragem sistemática por ser considerado mais exato, garantindo a distribuição mais uniforme das unidades pela área.

Em revisão de literatura observou-se que grande parte dos estudos utilizou o inventário por amostragem para avaliar a arborização urbana, como nas cidades de Pombal - PB (RODOLFO JÚNIOR et al, 2008), Campina Grande - PB (ARAÚJO et al, 2009), Assis - SP (ROSSATO et al, 2008), Morrinhos, Goiatuba e Caldas Novas - GO (SERPA et al, 2009), Piracicaba - SP (VOLPE-FILIK et al, 2007; SILVA FILHO et al, 2008) e Patos - PB (MELO et al, 2007).

O processo de amostragem do presente estudo baseou-se no trabalho de Meneghetti (2003), utilizando-se de amostragem sistemática, tendo o quarteirão como unidade amostral (denominada "quadra") e buscando uma intensidade amostral de 10\%. Inicialmente foram enumeradas as quadras dos dois conjuntos habitacionais sob análise. Em seguida foi realizado o sorteio da primeira quadra, e as demais foram selecionadas a cada dez unidades, sendo excluídas as que fossem ocupadas por áreas verdes.

\section{Variável Principal}

De acordo com Meneghetti (2003) a abundância de árvores pode ser expressa pelo número de árvores por quilômetro de calçadas, sendo esta uma variável de manejo simples, rápido e muito viável para fins de inventários de arborização urbana. Ela é definida pela razão entre o número de árvores amostradas e a somatória dos comprimentos das calçadas dos quarteirões que compõe a amostra.

\section{Variáveis qualitativas}

As variáveis qualitativas usadas neste estudo foram adaptadas dos estudos de Meneghetti (2003), Mascaró e Mascaró (2005) e Romero (2001). E os dados foram coletados com auxilio da ficha de campo.

\section{Variáveis relacionadas à quadra:}

- Número do quarteirão ao qual pertence;

- Nome da rua correspondente;

- Largura da calçada, em metros, medida com trena metálica;

- Tipo de ocupação da quadra (residencial, comercial, mista);

\section{Variáveis relacionadas ao indivíduo}

- Numero da árvore, conforme numeração sequencial de cada árvore amostrada;

- Nome popular e nome científico da espécie botânica; 
Gallo D. L. L.; Logsdon L.; Arborização de acompanhamento viário em conjuntos habitacionais de Cuiabá-MT. E\&S - Engineering and Science, (2017), 6:1.

Variáveis relacionadas ao tamanho dos indivíduos (porte da planta):

- "A", para alturas até a rede telefônica - 0 a 4,5 metros;

- "B", para alturas até a rede secundária - de 4,5 a 6,7 metros;

- "C", para alturas até a rede primária - de 6,7 a 8,2 metros

- "D", para alturas acima da rede primária - superiores a 8,2 metros;

Compatibilidade da espécie da árvore com relação ao local de plantio:

- "A"- adequada;

- "B" - pequena para o espaço;

- "C" - parcialmente compatível, devido a presença de fiação (árvores de crescimento monopodial e árvores submetidas a podas drásticas);

- "D" - parcialmente compatível, devido a outros motivos (frutos grandes, palmeiras, arbustos...);

- "E" - inadequada devido ao sistema radicular;

- "F" - grande para o espaço disponível (observação in loco);

\section{APRESENTAÇÃO E DISCUSSÃO DOS RESULTADOS}

A análise dos dados dos seis quarteirões que compuseram a amostra do estudo apresentou como resultado a presença de 245 árvores plantadas em 3.542 metros lineares de acompanhamento viário, o que representa a média aproximada de 1 árvore a cada 14 metros de calçada, ou 69 árvores por quilômetro de calçada. Esta quantidade está abaixo do considerado ideal pela Sociedade Brasileira de Arborização Urbana, que seria de pelo menos 100 indivíduos por km de calçada (PAIVA, 2009). A distribuição das árvores por loteamento estudado se encontra na Tabela 1.

Tabela 1 - Distribuição das árvores por loteamento estudado, metragem das quadras e abundância de árvores.

\begin{tabular}{lrrr}
\hline & $\begin{array}{c}\text { Morro de Santo } \\
\text { Antônio }\end{array}$ & Altos do Parque & TOTAL \\
\hline Quantidade de quadras & 3 & 3 & 6 \\
\hline Dimensão das calçadas (m) & 1.792 & 1.750 & 3.542 \\
\hline Quantidade de árvores & 180 & 65 & 245 \\
\hline Distância entre árvores (m) & 9,95 & 26,92 & 18,435 \\
\hline Árvores por km de calçada & 100 & 37,15 & 68,575 \\
\hline
\end{tabular}

A maioria das árvores pôde ser identificada in locu, prevalecendo a espécie Oiti (Moquilea tomentosa) representando 61,22\% do total de espécies, seguida do Jasmim Manga (Plumeria rubra) com 7,35\% e do Coqueiro (Cocos nucifera) com 6,53\%. Em torno de 6\% das espécies ainda não puderam ser identificadas, nem in locu nem com auxílio de bibliografia especializada. A distribuição das espécies pode ser observada na Tabela 2.

Ao considerar os loteamentos separadamente, percebe-se que no Altos do Parque prevalece a espécie Jasmim Manga $(27,69 \%)$ e no Santo Antônio a concentração é ainda maior, tendo a espécie Oiti com $82,22 \%$ do total de árvores plantadas.

A alta concentração de poucas espécies é evidente também em outros estudos, Araújo et al (2009) e Rodolfo Junior et al (2008) encontraram a prevalência da espécie Ficus (Ficus benjamina) em seus estudos. Nesta pesquisa, o Ficus não teve uma grande representatividade $(0,82 \%)$ nos loteamentos estudados, mas sim o Oiti, com $61,22 \%$ de frequência de ocorrência. Importante ressaltar que a maioria dos autores admite que uma espécie não deveria ultrapassar 
Gallo D. L. L.; Logsdon L.; Arborização de acompanhamento viário em conjuntos habitacionais de Cuiabá-MT. E\&S - Engineering and Science, (2017), 6:1.

15\% de toda a população arbórea (Melo, Lira Filho e Rodolfo Júnior, 2007; Rodolfo Júnior et al, 2008).

Tabela 2 - Distribuição das espécies e sua frequência.

\begin{tabular}{llrr}
\hline \multicolumn{1}{c}{$\begin{array}{c}\text { Nome } \\
\text { popular }\end{array}$} & \multicolumn{1}{c}{$\begin{array}{c}\text { Nome } \\
\text { científico }\end{array}$} & Quan-tidade & Fre-quência (\%) \\
\hline Oiti & Licania tomentosa & 150 & 61,22 \\
\hline Jasmim manga & Plumeria rubra & 18 & 7,35 \\
\hline Coqueiro & Cocos nucifera & 16 & 6,53 \\
\hline Murta & Myrtus communis & 14 & 5,71 \\
\hline Paineira & Ceiba speciosa & 8 & 5,71 \\
\hline Espirradeira & Nerium oleander & 3 & 3,27 \\
\hline Limoeiro & Citrus limon & 3 & 1,81 \\
\hline Mangueira & Mangifera indica & 2 & 1,81 \\
\hline Ficus & Ficus benjamina & 2 & 0,82 \\
\hline Ipe de jardim & Tecoma stans & 2 & 0,82 \\
\hline Pata de vaca & Bauhinia variegata & 1 & 0,82 \\
\hline Cajueiro & Anacardium occidentale & 1 & 0,41 \\
\hline Goiabeira & Psidium guajava & 1 & 0,41 \\
\hline Ipê & Tabebuia sp & 1 & 0,41 \\
\hline Palmeira & Arecaceae & 8 & 0,41 \\
\hline Resedá & Lagerstroemia indica & $\mathbf{2 4 5}$ & 0,41 \\
\hline Não identificada & $-------------~$ & 5,71 \\
\hline Total & & $\mathbf{4 0 0 , 0 0}$ \\
\hline
\end{tabular}

Figura 1 - Arborização viária do Residencial Morro de Santo Antônio.

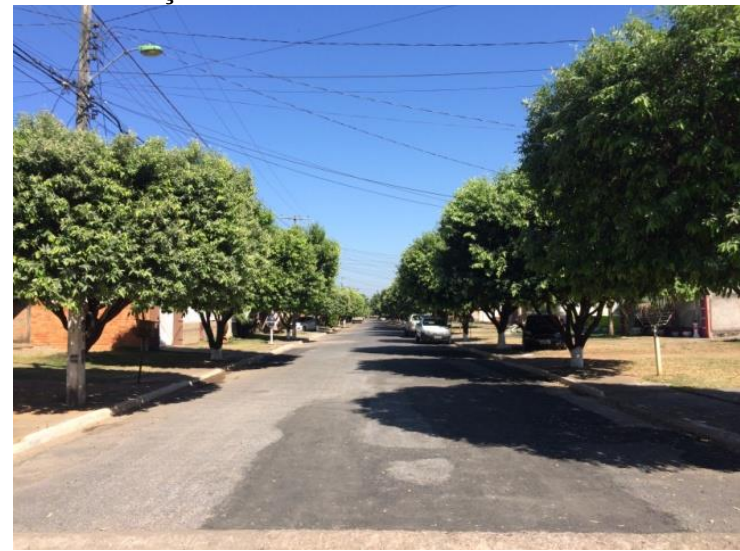

FONTE: Os autores (2015).

Quanto ao porte das árvores observadas tem-se que a maioria $(71,43 \%)$ é de pequeno porte, ou seja, sua copa não ultrapassa a fiação da rede primária (Tabela 3). Em muitos casos este percentual é devido a podas e topiaria frequentes, especialmente na espécie mais predominantes (Oiti). Os dados diferem do encontrado na cidade de Santos (MENEGHETTI, 2003), onde a maior parte dos indivíduos arbóreos ultrapassava a rede secundária de energia.

Tabela 3 - Porte das árvores tendo como referência a rede de energia.

\begin{tabular}{lrr}
\hline Porte & Frequência & Porcentagem (\%) \\
\hline A - altura até a rede telefônica & 175 & 71,43 \\
\hline B - altura até a rede secundária & 60 & 24,49 \\
\hline C - altura até a rede primária & 4 & 1,22 \\
\hline D - altura acima da rede primaria & 3 & 1,22 \\
\hline não identificada & 4 & 1,63 \\
\hline Total & $\mathbf{2 4 5}$ & $\mathbf{1 0 0 , 0 0}$ \\
\hline
\end{tabular}


Gallo D. L. L.; Logsdon L.; Arborização de acompanhamento viário em conjuntos habitacionais de Cuiabá-MT. E\&S - Engineering and Science, (2017), 6:1.

Já em relação à compatibilidade da espécie com o local, 46,53\% das árvores está adequada, seguido de 37,96\% grandes para o espaço disponível (Tabela 4). No estudo de Meneghetti (2003) a maior frequência de árvores eram inadequadas devido ao sistema radicular, seguido das plantas adequadas.

Tabela 4 - Compatibilidade da arborização urbana com relação à espécie utilizada.

\begin{tabular}{lrr}
\hline \multicolumn{1}{c}{ Compatibilidade } & Frequência & Porcentagem (\%) \\
\hline A - adequada & 114 & 46,53 \\
\hline B - pequena para o espaço disponível & 0 & 0,00 \\
\hline $\begin{array}{l}\text { C - parcialmente compatível, devido } \\
\text { presença de fiação }\end{array}$ & 24 & 9,80 \\
\hline $\begin{array}{l}\text { D - parcialmente compatível, devido a } \\
\text { outros motivos }\end{array}$ & 3 & 1,22 \\
\hline $\begin{array}{l}\text { E - inadequada devido ao sistema } \\
\text { radicular }\end{array}$ & 2 & 0,82 \\
\hline F - grande para o espaço disponível & 93 & 37,96 \\
\hline Não identificada & 9 & 3,67 \\
\hline Total & $\mathbf{2 4 5}$ & $\mathbf{1 0 0 , 0 0}$ \\
\hline
\end{tabular}

A análise da compatibilidade das espécies com o calçamento indicou que na maioria dos casos $(55,51 \%)$ a calçada apresentava danos leves, como pode ser observado na Tabela 5.

Tabela 5 - Compatibilidade das espécies utilizadas na arborização com o calçamento.

\begin{tabular}{lrrr}
\hline \multicolumn{1}{c}{ Qualidade das calçadas } & Frequência & \multicolumn{2}{c}{ Porcentagem (\%) } \\
\hline A - danos severos ao calçamento & 2 & 0,82 \\
\hline B - danos leves ao calçamento & 136 & 55,51 \\
\hline C - calçada em bom estado & 96 & 39,18 \\
\hline Não identificada & 11 & 4,49 \\
\hline Total & $\mathbf{2 4 5}$ & $\mathbf{1 0 0 , 0 0}$ \\
\hline
\end{tabular}

\section{CONSIDERAÇÕES FINAIS}

Observou-se uma diferença expressiva entre os dois conjuntos habitacionais, sendo que o mais antigo - o Residencial Morro de Santo Antônio - tem uma quantidade de árvores considerada satisfatória para os parâmetros recomendados, embora tenha baixa variabilidade de espécies. Já o loteamento mais recente, Altos do Parque, necessitaria do plantio de pelo menos 110 novas árvores para conseguir uma quantidade adequada de uma árvore a cada 10 metros de calçada. Outra característica deste último loteamento é que o projeto adotou uma espécie arbórea/arbustiva específica para cada quarteirão, o que pode não ser interessante do ponto de vista biológico, devido à facilidade de alastramento de eventuais pragas.

A segunda constatação é a pequena diversidade de espécies. Uma maior diversificação das espécies é necessária, em particular utilizando espécies nativas do cerrado, para proporcionar uma valorização de referências ecológicas e paisagísticas que promovam maior biodiversidade e possam contribuir para a qualidade ambiental da paisagem urbana.

\section{AGRADECIMENTOS}

Ao Instituto Federal de Mato Grosso (IFMT - Campus Cuiabá) e ao Instituto Federal de São Paulo (IFSP - Campus Registro), pelo apoio à pesquisa.

À Universidade Federal de Mato Grosso (UFMT) e, em especial, à Faculdade de Arquitetura, Engenharia e Tecnologia (FAET) e ao Instituto de Ciências Exatas e da Terra (ICET), pela publicação e editoração deste periódico. 
Gallo D. L. L.; Logsdon L.; Arborização de acompanhamento viário em conjuntos habitacionais de Cuiabá-MT. E\&S - Engineering and Science, (2017), 6:1.

Aos alunos do IFMT que auxiliaram na coleta de dados: Ana Clara Marques de Lima; Henrique Alexandre Rondon; Matheus Yan Almeida Soares Kurpel Daron e Laisa Vasconcelos Araújo.

\section{REFERÊNCIAS BIBLIOGRÁFICAS}

AMORE, C. S. "Minha Casa, Minha Vida" para iniciantes. In: AMORE, C; SHIMBO, L. Z.; RUFFINO, M. B. C. (org.) Minha casa... e a cidade? Avaliação do programa minha casa minha vida em seis estados Brasileiros. Rio de Janeiro: Letra Capital, 2015. Disponível em: <http://www.obser vatoriodasmetroples.net/images/abook_file /mcmv_nacional2015.pdf>. Acesso em agosto de 2015.

ARAÚJO, Afrânio César de ; et al. Análise quali-quantitativa da arborização no bairro presidente Médici, Campina Grande - PB. REVSBAU, Piracicaba - SP, v.4, n.1, p.133-144, 2009.

BONDUKI, Nabil. Origens da Habitação Social no Brasil. 4. ed. São Paulo: Estação Liberdade, 2004.

BOTEGA, Leonardo da Rocha. De Vargas a Collor: urbanização e política habitacional no Brasil. Revista Espaço Plural. Ano VIII nº 17, p. 65 -72 2º semestre 2007.

BRASIL. Lei $\mathbf{n}^{\mathbf{0}}$ 11.977, de 7 de julho de 2009. Dispõe sobre o Programa Minha Casa, Minha Vida - PMCMV e a regularização fundiária de assentamentos localizados em áreas urbanas; altera o Decreto-Lei no 3.365, de 21 de junho de 1941, as Leis nos 4.380, de $21 \mathrm{de}$ agosto de 1964, 6.015, de 31 de dezembro de 1973, 8.036, de 11 de maio de 1990, e 10.257, de 10 de julho de 2001, e a Medida Provisória no 2.197-43, de 24 de agosto de 2001; e dá outras providências.

CASTOR, R. S. Núcleos habitacionais de interesse social em Mato Grosso: Condições originais e atuais. In: II Seminário Mato-Grossense de Habitação de Interesse Social, 2007, Cuiabá-MT. Anais. CD-ROM.

COSTA, R. G. S.; FERREIRA, C. C. M. Análise do índice de áreas verdes (IAV) na área central da cidade de Juiz de Fora, MG. REVSBAU. Piracicaba - SP, v.4, n.1, p. 39-57, 2009.

HUTHER, M. C.; MASCARÓ, J. J. Análise qualitativa da arborização urbana em bairros de diferentes classes sociais. Malha Urbana, Revista Lusófona de Urbanismo. Lisboa - PT, v.4, n.6, 2008.

FUNDAÇÃO JOÃO PINHEIRO. Déficit habitacional no Brasil 2011-2012. Belo Horizonte, 2015. Disponível em: <http://www.fjp.mg.gov.br/index.php/docman/cei/559-deficit-habita cional-2011-2012/file >. Acesso em junho de 2015.

KOWARICK, L; BONDUKI, N. Espaço urbano e espaço político: do populismo à redemocratização. In: As lutas sociais e a cidade: São Paulo, passado e presente. KOWARICK, L. (org.). Rio de Janeiro: Paz e Terra, 1988.

MARICATO, Ermínia. Brasil, cidades: alternativas para a crise urbana. 5.ed. Petrópolis: Vozes, 2011. 
Gallo D. L. L.; Logsdon L.; Arborização de acompanhamento viário em conjuntos habitacionais de Cuiabá-MT. E\&S - Engineering and Science, (2017), 6:1.

MASCARÓ, Lucia; MASCARÓ, Juan. Vegetação Urbana. Porto Alegre: Mais Quatro Editora, 2.ed.: 2005.

MELO, Rafael Rodolfo de; LIRA FILHO, José Augusto de; RODOLFO JÚNIOR, Francisco. Diagnóstico qualitativo e quantitativo da arborização urbana no bairro Bivar Olinto, Patos, Paraíba. REVSBAU, Piracicaba - SP, v.2, n.1, 2007.

MENEGHETTI, Gabriela Ignarra Pedreira. Estudo de dois métodos de amostragem para inventário da arborização de ruas dos bairros da orla marítma do município de Santos, SP. Dissertação Mestrado em Recursos Florestais. Escola Superior de Agricultura "Luiz de Queiroz”, Universidade de São Paulo, 2003.

METELLO et al. Os programas habitacionais no Brasil: uma análise e resultados. In: I Seminário Mato-Grossense de Habitação de Interesse Social, 2005, Cuiabá-MT.

MILANO, M. S. . Métodos de amostragem para avaliação da arborização de ruas. In: II CONGRESSO BRASILEIRO DE ARBORIZAÇÃO URBANA, 1994, São Luis. Anais, 1994. v. 1. p. 163-168.

OLIVEIRA, F. A. C. et al. Inventário da Arborização do campus Pato Branco da Universidade Tecnológica Federal do Paraná - UTFPR. REVSBAU. Piracicaba - SP, v.4, n.1, p. 93-106, 2009.

OLIVEIRA, A. S. de. Influência da vegetação arbórea no microclima e uso de praças públicas. Tese (Doutorado). Programa de Pós Graduação em Física Ambiental. Universidade Federal de Mato Grosso. 2011.

PAIVA, Ary Vieira de. Aspectos da arborização urbana do centro de Cosmópolis-SP. REVSBAU, Piracicaba - SP, v.4, n.4, p.17-31, 2009.

RODOLFO JÚNIOR, Francisco; et al. Análise da Arborização Urbana em bairros da cidade de Pombal no Estado da Paraíba. REVSBAU, Piracicaba - SP, v.3, n.4, p.3-19, 2008.

ROMERO, Marta Adriana Bustos. A arquitetura bioclimática do espaço público. Brasília: Editora UnB, 2001.

SANTANA, L. S. Os vazios urbanos nos centros de cidades como lugar para a habitação de interesse social: $O$ caso de Maceió/AL. Dissertação (Mestrado em Dinâmicas do Espaço Habitado). Universidade Federal de Alagoas. 2006.

SANTOS, Milton. A urbanização brasileira. 5.ed. São Paulo: Editora da Universidade de São Paulo, 2013.

SERPA, Daiane Siqueira; et al. Arborização urbana em três municípios do sul do estado de Goiás: Morrinhos, Goiatuba e Caldas Novas. REVSBAU, Piracicaba - SP, v.4, n.3, p.98-112, 2009.

SILVA, Geovany Jessé Alexandre da. Parque linear da Prainha, Cuiabá-MT: uma ruptura de paradigmas na intervenção urbana. Dissertação (Mestrado em Geografia). Universidade Federal de Mato Grosso. Cuiabá, 2007. 
Gallo D. L. L.; Logsdon L.; Arborização de acompanhamento viário em conjuntos habitacionais de Cuiabá-MT. E\&S - Engineering and Science, (2017), 6:1.

SILVA FILHO, Demóstenes Ferreira; et al. Levantamento do potencial de arborização e proposta para três bairros no município de Piracicaba/SP, Brasil. REVSBAU, Piracicaba SP, v.3, n.4, p.20-39, 2008.

VILLAÇA, Flávio. O que todo cidadão precisa saber sobre habitação. São Paulo: Global, 1986.

VOLPE-FILIK, Andrea; et al. Avaliação da arborização de ruas do bairro São Dimas na Cidade de Piracicaba/SP através de parâmetros qualitativos. REVSBAU, Piracicaba - SP, v.2, n.1, 2007. 